\title{
Editorial Preface by the Editor-in-Chief
}

\section{International Journal of Doctoral Studies (Vol. 6)}

IJDS had another great year. We have seen a significant increase this year in articles submission. The IJDS editorial board members have been very busy throughout the year to maintain the quality of IJDS publications. The board has kept the tradition of excellence in quality publication for accepted papers.

This sixth volume of IJDS includes seven manuscripts. The first article by Barnes, Chard, Wolfe, Stassen, and Williams, "An Evaluation of the Psychometric Properties of the Graduate Advising Survey for Doctoral Students, " reported on a substantial endeavor of collecting survey data from nearly 2,400 graduate and doctoral students about the advising support they received during their academic experience. Their results suggested six sound dimensions and a validated instrument that practitioners can use to improve the quality of doctoral advising as well as support. The second article by Nutov and Hazzan, "Feeling the Doctorate: Is Doctoral Research that Studies the Emotional Labor of Doctoral Students Possible?" documented an intriguing question about the viability of conducting a doctoral dissertation about emotional labor during doctoral studies. They concluded that such research is productive, while it is possible to achieve only at the end of the doctoral endeavor. The third article by N. Dreher and H. Dreher, "Empowering Doctoral Candidates in Finding Relevant Concepts in a Literature Set, " reported on a great technique to empower doctoral students and novice researchers on the mechanics of literature attainment. The fourth article by V. Castro, Garcia, Cavazos, and A. Y. Castro, "The Road to Doctoral Success and Beyond," documented a qualitative research study using semi-structured interviews about women's success in a Ph.D. counseling program. Their findings suggested three main themes, attributes, attitudes, and motivations, as the key ingredients for success in such doctoral studies. The fifth article by Holley, "A Cultural Repertoire of Practices in Doctoral Education," discussed the role of culture as an active repertoire in doctoral studies. Her qualitative research using a group of 40 doctoral students indicated that cultural repertoire is central to their socialization. The sixth article by Jones and Alony, "Guiding the Use of Grounded Theory in Doctoral Studies - An Example from the Australian Film Industry," documented the use of Grounded Theory (GT) in doctoral dissertations. Their work documented an example from the Australian film industry as a context for the use of GT in doctoral research. The last article of this IJDS volume by Wao and Onwuegbuzie, "A Mixed Research Investigation of Factors Related to Time to the Doctorate in Education," reported on an exploratory research study using mixed-methods approach on a sample of over 1,000 doctoral students about time to attainment of the doctorate (TTD) degree. Their findings provide some insights into the critical factors that have significant impact on TTD.

As in prior years, I would like to thank the IJDS advisory board members, Prof. Marc Schniederjans, C. Wheaton Battey Distinguished Professor, University of Nebraska-Lincoln, NE (USA) and Prof. Niv Ahituv, The Marko and Lucie Chaoul Chair for Studies in Information Evaluation Academic, Academic Director of the Institute for Internet Studies, Tel Aviv University (Israel) for their continuous support of IJDS. Furthermore, I would like to thank the IJDS associate editors for their exceptional work and continuous support to IJDS including (in alphabetical order of last names): Nicole Buzzetto-More, University of Maryland Eastern Shore (USA), Sue Conger (University of Dallas, USA), Nitza Geri (The Open University of Israel, Israel), George M. Marakas (University of Kansas, USA), Bernd Carsten Stahl (De Montfort University, UK), Steven R. Terrell, Nova Southeastern University (USA), and Victoria Wise, Deakin University (Australia). Additionally, I would like to welcome Chaya Herman, University of Pretoria (South Africa) who agreed to serve IJDS in the capacity of associate editor (AE). Chaya has been doing exceptional reviews for IJDS in prior years and her dedicated work is truly appreciated. We are 
grateful by the dedication and the hard work you all provide to the research community via IJDS. Your dedicated service and outstanding support are mirrored in the achievements and continuous success of IJDS. Separately, I would like to thank my assistant to the editor-in-chief, Michael Reid, Loma Linda University (USA), for his continuous assistance. Moreover and as in prior years, I would like to highlight and proudly thank for the group of outstanding International Review Board members who served as reviewers for one or more manuscripts submitted this year to IJDS (in alphabetical order of last name):

- Azad Ali, Indiana University of Pennsylvania (USA)

- Peter H. Antoniou, California State University - San Marcos (USA)

- Geoff Berry, Macquarie Education Group (Ausralia)

- Harvey Brightman, Georgia State University (Emeritus, USA)

- Susan Carter, University of Auckland (New Zealand)

- Heinz V. Dreher (Australia)

- Tim Duffy, University of the West of Scotland (UK)

- Sarah Earl-Novell, University of California Berkeley (USA)

- Tillal Eldabi, Brunel University (UK)

- Tim Ellis, Nova Southeastern University (USA)

- James C. Flowers, Ball State University (USA)

- Orit Hazzan, Technion - Israel Institute of Technology (Israel)

- Barbara Holmes, Argosy University (USA)

- Angela Kydd, University of the West of Scotland (UK)

- Cecilia Sik Lanyi, University of Pannonia (Hungary)

- Jayantha P. Liyanage, University of Stavanger (Norway)

- Anthony Nichols, Shorter University (USA)

- Dana Nicolau, Victoria University (Australia)

- Michael Reid, Loma Linda University (USA)

- Cynthia Ruppel, Nova Southeastern University (USA)

- Peter Sandiford, Manchester Metropolitan University (UK)

- Peter Smith, University of Sunderland (UK)

- Amanda Spink, Loughborough University (UK)

- Dorian Stoilescu, University of Toronto (Canada)

- Darla Twale, University of Dayton (USA)

- Vishwa Mohan Vangari, Osmania University (India)

- Kam Vat, University of Macau (Macau/China)

- Ling Wang, Nova Southeastern University (USA)

- Hesborn Wao, University of Central Florida (USA)

- Hadas Weinberger, HIT - Holon Institute of Technology (Israel)

- Trevor Wilmshurst, University of Tasmania (Australia)

- Benjamin Tak Yuen Chan, Open University of Hong Kong (Hong Kong)

Throughout this past year, you all have done an amazing work that is the envy of many quality peer-review journals. We're honored to have you on our review board and for the valuable contributions you provided to authors. Your mentorships and substantial review comments to authors of all articles worthy of IJDS review are what made IJDS the world premier scholarly peerreviewed journal on doctoral studies.

IJDS continues to welcome quality submissions on research related to doctoral studies in all fields of research that offers doctoral degrees including (but certainly not limited to) arts, business, computer science, criminal justice, decision sciences, education, engineering, health, humanities, 
information technology, information systems, law, medicine, management, nursing, oceanography, psychology, sciences, social studies, and inter-disciplinary doctoral programs. Book reviews on relevant issues related to doctoral studies are also welcome.

IJDS continue to welcome quality and qualified reviewers to serve in all levels of our editorial board. If you, or someone you know, have been involved or have experience with doctoral students' supervisions, teaching doctoral level courses, serving on doctoral dissertations, or guiding doctoral research in any field of research and are willing to contribute as a reviewer of at least three papers a year, we would like to have you as part of our editorial team. If you would like to join the IJDS editorial review board or wish to nominate someone you know, please e-mail me your CV or resume with brief note on your experiences noted above (or the credential of the person you're nominating). Please note that experience with one or more activities noted above is a requirement to serve on the IJDS editorial board.

IJDS is the world premier scholarly peer-reviewed journal on doctoral studies. We truly appreciate all the support provided by the individuals noted above and the members of the Informing Science Institute (ISI). We hope you will enjoy the articles found in this year's volume.

Yair Levy, Ph.D. - Nova Southeastern University (USA)

Editor-in-Chief

editor@ijds.org

\section{Biography}

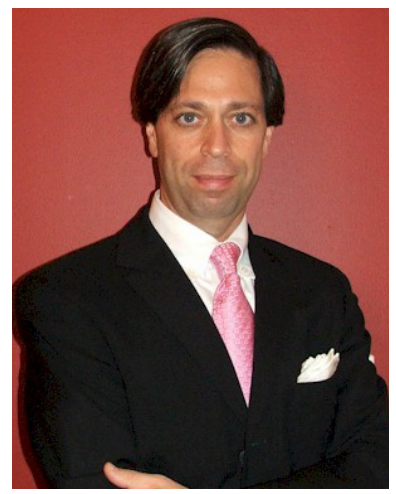

Dr. Yair Levy is an Associate Professor at the Graduate School of Computer and Information Sciences at Nova Southeastern University. During the mid to late 1990s, he assisted NASA to develop e-learning systems. He earned his Bachelor's degree in Aerospace Engineering from the Technion (Israel Institute of Technology). He received his MBA with Management Information Systems concentration and Ph.D. in Management Information Systems from Florida International University. His current research interests include cognitive value of IS, of online learning systems, effectiveness of IS, and cognitive aspects of IS. Dr. Levy is the author of the book "Assessing the Value of eLearning systems." His research publications appear in the IS journals, conference proceedings, invited book chapters, and encyclopedias. Additionally, he chaired and co-chaired multiple sessions/tracks in recognized conferences. Currently, Dr. Levy is serving as the Editor-in-Chief of the International Journal of Doctoral Studies (IJDS). Moreover, he is serving as an associate editor and as a member of editorial review or advisory board of several refereed journals. Additionally, Dr. Levy has been serving as a referee research reviewer for numerous national and international scientific journals, conference proceedings, as well as information systems and information security textbooks. He is also a frequent speaker at national and international meetings on information and online learning systems topics. To find out more about Dr. Levy, please visit his site: http://scis.nova.edu/ levyy/ 